RESOURCES
Where to get help
In the United States:
Grad Resources
www.gradresources.org
The Jed Foundation
www.jedfoundation.org
ULifeline
www.ulifeline.org
Campus Mind Works
www.campusmindworks.org
In the United Kingdom:
Mental Wealth
www.mentalwealthuk.com
Student Counselling
www.student.counselling.co.uk
Students Against Depression
www.studentsagainstdepression.org

your worries with," says Sharon Milgram, director of the NIH Office of Intramural Training and Education. Wallace suggests that postgraduates talk to a university-based counsellor about what can be gained by confiding, and what level of detail is appropriate. "If a postgraduate feels some level of disclosure would help their adviser understand their recent behaviour, it may suffice to simply say, 'I've been having problems and I'm getting help for it," says Wallace.

Data from the United States and the United Kingdom suggest that counselling helps the vast majority of students to get past personal problems and excel. To be successful, people must take care of themselves, notes Milgram. "Getting help," she says, "is a sign of strength, not weakness." -

Virginia Gewin is a freelance writer based in Portland, Oregon.

1. Radison, K. \& DiGeronimo, T. F. College of the Overwhelmed (Jossey-Bass, 2005).

2. Gallagher, R. P. National Survey of Counseling Center Directors 2011 (International Assoc. of Counseling Services, 2011).

3. Royal College of Psychiatrists Mental health of students in higher education College Report CR166 (2011).

4. Davis, G. Am. Scientist 93, (3) Supplement http://postdoc.sigmaxi.org/results/ (2005).

\footnotetext{
CORRECTION

The story 'A voice for the voiceless'

(Nature 489, 461-463; 2012) incorrectly

stated that the US National Postdoctoral

Association (NPA) is working with

the Association of Public Land-grant

Universities to develop a certification programme. The NPA is developing the programme on its own but will seek support and input from the university association.
}

\title{
COLUMN
}

\section{Advising on the edge}

\section{Interdisciplinary mentorship must evolve to keep pace with innovative programmes, argues Katherine Mackey.}

$\mathrm{M}$ ore than ever, scientists are working across disciplines. Addressing and analysing climate change, sustainable development and genomic data requires unusual and interdisciplinary approaches. As problems and solutions co-evolve in unexpected ways, skill sets must evolve too - as must mentorship. Mentors should work to bring early-career scholars up to speed on issues such as funding structures and communication styles tailored to interdisciplinary efforts - and protégés should be proactive.

Interdisciplinary work often takes root in an established department. Scholars must function in the existing framework, even when the goals, timelines and deliverables of the research differ. So when the research grows into its own programme, the first scholars to seek tenure in it will have no mentors who have navigated the same process. As early-career researchers attempt to break new ground, they must seek the few interdisciplinary mentors who can help them to find their bearings.

Young scholars should cast a wide net. Mentors from other disciplines may provide fresh perspectives, and their enthusiasm for collaborating can build an early-career researcher's confidence. But interdisciplinary scholars still need strong mentors in their own programmes, who are sensitive to extra-departmental obligations and can help them to keep pace with deadlines and degree or tenure requirements.

To ensure that their protégés get used to the culture of multiple disciplines, mentors should help students to identify and forge collaborations with other experts. This might include arranging training in different laboratories or universities, to build networks from which interdisciplinary progress can grow.

\section{SPECIAL CHALLENGES}

Logistics set interdisciplinary mentorship apart. For students, the need for course work and training in both a disciplinary department and an interdisciplinary programme can double early-stage time commitments and delay dissertation projects. It is essential for advisers and committee members to communicate with the student and each other to prioritize training objectives.

Early-career researchers on the tenure track face more serious challenges: owing to lack of precedent, institutional variability and multidisciplinary tenure committees, expectations

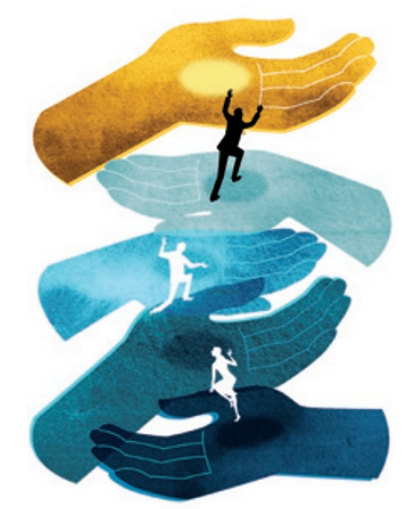

may not be well established. How many first-authored papers should be written per year? By when should the first grant be funded? How many courses should be developed and/ or taught each year? All of these milestones can vary between disciplines.

Committee or department chairs should issue annual progress reports to ensure that a scientist's research goals mesh with the department's needs. This gives the scholar a chance to adapt their research early on, to include angles or activities that the department values.

The challenge isn't just about understanding benchmarks, but also about finding ways to receive credit for unusual, difficult-toevaluate work such as science-policy statements, decision-support systems and outreach tools. And it may not be clear whether or how extra-departmental courses, multi-authored projects or shared graduate students (who gets credit for mentoring them?) will count towards tenure requirements.

Mentors can clarify how these achievements will be 'scored' during the tenure process. And they should strive to help protégés to understand the opinions and expectations of committee members by, for example, facilitating discussions about how progress is charted.

As interdisciplinary scholars look for innovative solutions, their mentors must also develop innovative approaches. This will help the protégés to enrich their education and earn useful degrees - and chart a course towards a successful career.

Katherine Mackey is a US National Science Foundation biology fellow at the Woods Hole Oceanographic Institution and the Marine Biological Laboratory in Woods Hole, Massachusetts. 